ISSUES AND INNOVATIONS IN NURSING PRACTICE

\title{
The implementation of a Pain Monitoring Programme for nurses in daily clinical practice: results of a follow-up study in five hospitals
}

\author{
Marlies de Rond MS PhD RN \\ Nurse Scientist, Comprehensive Cancer Centre, Amsterdam, and The Netherlands Cancer Institute/Antoni van Leeuwenhoek \\ Hospital, Amsterdam, The Netherlands
}

Rianne de Wit MS PhD

Nurse Scientist, Head of the Pain Expertise Centre, University Hospital Rotterdam, Department of Medical Psychology and Psychotherapy, Erasmus University, Rotterdam, The Netherlands

and Frits van Dam PhD

Professor in Medical Psychology, The Netherlands Cancer Institute/Antoni van Leeuwenhoek Hospital, and Department of Clinical Psychology, Faculty of Psychology, University of Amsterdam, Amsterdam, The Netherlands

Submitted for publication 15 September 2000

Accepted for publication 4 May 2001

Correspondence:

Frits van Dam,

Netherlands Cancer Institute/Antoni van

Leeuwenhoek Hospital,

Department of Psychosocial Research and Epidemiology,

Plesmanlaan 121

1066 CX Amsterdam,

The Netherlands.

E-mail:fvandam@nki.nl
DE ROND M., DE WIT R. \& VAN DAM F. (2001) Journal of Advanced Nursing 35(4), 590-598

The implementation of a Pain Monitoring Programme for nurses in daily clinical practice: results of a follow-up study in five hospitals

Aims of the study. To study the effects of the implementation of a Pain Monitoring Programme (PMP) for nurses in daily clinical practice. In addition, nurses' and physicians' pain knowledge and attitudes were studied, as well as change in nurses' pain knowledge after implementation of the programme.

Rationale. The rationale for the study was that many hospitalized patients suffer from pain and treatment of pain is often inadequate.

Background. Reasons for inadequate treatment of pain are the failure of nurses to assess pain on a daily basis and insufficient knowledge about pain and pain management in both nurses and physicians. The PMP tried to overcome these barriers by implementing daily pain assessment and educating nurses about pain and pain management.

Research methods. This follow-up study was conducted in five hospitals. In total, 277 nurses and 115 physicians participated. The implementation and long-term effects of the programme were measured with a pretest-post-test design without a control group.

Results. Results showed that nurses carried out daily pain assessment in at least $75 \%$ of patients during the first 5 months of the intervention period, but in the remaining 2 months professional compliance gradually decreased. Both nurses and physicians are positive about daily pain assessment and want to continue with it. The level of nurses' and physicians' knowledge about pain and pain management is moderate. The programme increased nurses' knowledge and satisfaction regarding the quality of pain treatment. 
Discussion. Because professional compliance decreased after 5 months, incentives are needed to motivate nurses to continue with daily pain assessment. Continuous Quality Improvement may be a useful method to guide the implementation process. Conclusions. Based on these results it can be concluded that it is possible to implement the PMP in daily clinical practice. Moreover, the beneficial effects of our programme on nurses' knowledge and attitudes have been demonstrated. Therefore, participating hospitals were advised to continue and extend the programme and other hospitals are encouraged to implement it.

Keywords: pain education, daily pain assessment, pain knowledge, attitudes, nurses, physicians

\section{Introduction}

Many hospitalized patients suffer from a variety of types of pain which are not always adequately managed (Dorrepaal et al. 1989, Coyle et al. 1990, Kuhn et al. 1990, Juhl et al. 1993, Lin \& Ward 1995, De Wit et al. 1999). A complexity of factors are responsible for this poor state of affairs, including insufficient knowledge of nurses and physicians about pain management (Jacox et al. 1994, McCaffery \& Ferrell 1995, Clarke et al. 1996, Lebovits et al. 1997). In addition, both nurses and physicians lack knowledge about opioid analgesic drugs and have misconceptions about addiction, tolerance, etc. (Fife et al. 1993, Von Roenn et al. 1993, Ferrell \& McCaffery 1997, McCaffery \& Ferrell 1997, Furstenberg et al. 1998).

Failure to assess pain on a daily basis is another reason for inadequate pain management. When pain is not assessed in a systematic way, it is difficult to determine the effect of a pain treatment and, if necessary, to adjust this treatment (Donovan 1985, Jacox et al. 1992, American Pain Society Quality of Care Committee 1995). Nevertheless, assessment of pain complaints does not have to be difficult; an earlier study demonstrated the feasibility of nurses assessing their patients' pain twice a day, after having participated in an education programme on pain and pain relief (De Rond et al. 1999). Nurses asked patients to score the severity of their pain twice a day from 0 (no pain) to 10 (worst pain imaginable) and recorded results on the vital signs chart. Daily pain assessment could be easily integrated into the nurses' daily routine (De Rond et al. 1999), and the education programme led to an improvement in their pain knowledge (De Rond et al. 2000b). As a result of the programme, nurses were more aware of their patients' pain complaints and documented more information about pain in the nursing records (De Rond et al. 2000a). The ultimate goal of the programme was to optimize pain relief and decrease pain complaints by patients. This goal was met, because the programme led to a decrease in patients' pain intensity (De Rond et al. 2001).

Thus, monitoring pain and educating nurses is feasible when they are introduced and integrated as part of a research programme. Implementation of this Pain Monitoring Programme (PMP) was performed in the setting of a dedicated study, in which research nurses were present on the wards daily to interview patients and stimulate pain assessment. Furthermore, research nurses were able to promote the use of newly acquired knowledge.

This paper describes a study in which a PMP was implemented in clinical practice without the use of any extra facilities, such as the availability of research nurses. Implementation of daily pain assessment combined with pain education in clinical practice has been studied by several groups as part of Continuous Quality Assessment/Improvement Programmes (Dietrick-Gallagher et al. 1994, Titler et al. 1994, Bach 1995, Dufault et al. 1995, Ferrell et al. 1995, Bookbinder et al. 1996, Campese 1996, Caswell et al. 1996). These latter studies came to similar conclusions, as reported by De Rond et al. (1999, 2000a, 2000b, 2001), but most of these studies comprised small homogeneous study groups (mostly cancer patients), the outcome measures were not always clearly defined, and only one study investigated nurses' professional compliance with daily pain assessment (Bookbinder et al. 1996).

\section{The study}

\section{Aim}

The aim of the present study was to investigate whether implementation of the PMP is feasible in clinical practice and to investigate the long-term effects of the programme. We evaluated the effects of the programme on nurses' pain knowledge, nurses' understanding of patients' pain complaints, and the quality of pain management. Finally, we 
studied the knowledge and attitudes of physicians towards pain management. We hypothesized that the PMP would improve nurses' pain knowledge, resulting in a better understanding of patients' pain complaints and improved quality of pain management.

\section{Method}

\section{Sample}

The programme was carried out in five general hospitals in the same programme region as the Comprehensive Cancer Centre Amsterdam. A total of 11 wards (six medical, four surgical and one mixed) with 277 nurses and 115 physicians participated.

\section{Design}

The effect of the PMP on nurses' pain knowledge was studied in a pretest-post-test design without a control group. Prior to implementation of the programme nurses filled in a questionnaire about pain and pain management. During the implementation period, data were collected about the extent to which nurses assessed pain systematically. Seven months after implementation of the PMP, nurses' pain knowledge and attitudes were assessed for a second time, and their opinion on daily pain assessment was evaluated. In addition at this stage, physicians were surveyed about pain and pain management.

\section{Procedures: the Pain Monitoring Programme}

From June 1996 to February 1998, the PMP was introduced on 11 wards in five hospitals. The purpose of the programme was to improve nurses' assessment of patients' pain and to increase nurses' pain knowledge, and thereby optimize pain relief and reduce pain complaints.

Prior to implementation of daily pain assessment, all nurses followed an education programme lasting 3 hours. This consisted of a lecture and discussion, and focused on basic knowledge and attitudes about current trends in pain assessment, pain treatment with analgesics and the use of nonpharmacological pain treatment. Physicians received only written information about the programme, and were briefly instructed about the basic principles of pain management. After all nurses had followed the education programme, daily pain assessment was implemented in nursing practice. Patients were asked twice a day by nurses to rate their present pain on an 11-point numeric rating scale, on which 0 represents 'no pain at all' and 10 'the worst possible pain'. Nurses charted the pain scores on the vital signs chart, so that patients' pain intensity, as well as the effectiveness of pain treatment, could be quickly determined by both nurses and physicians.

\section{Measures}

The implementation of daily pain assessment was evaluated by means of establishing nurses' professional compliance and a questionnaire which measured nurses' and physicians' opinions about daily pain assessment. To establish nurses' professional compliance, pain scores from the nursing records were collected. Using these data, we calculated how often nurses assessed pain: the number of pain scores recorded on the vital signs chart was divided by the maximum number of pain scores possible. Nurses' professional compliance was assessed twice a month in the first 2 months, and then once a month; this means that each time about 300 nursing records were checked in the five hospitals. When nurses assessed pain in more than $75 \%$ of the patients, compliance was deemed satisfactory (De Rond et al. 1999).

Nurses' and physicians' opinions about daily pain assessment were evaluated with the Daily Pain Assessment Questionnaire (DPAQ) at post-test (De Rond et al. 1999). This questionnaire covers the following issues: nurses' attitudes to daily pain assessment, the feasibility of daily pain assessment, problems in eliciting a pain score, timing of daily pain assessment, and the effect of daily pain assessment on communication. Nurses could answer on a 5-point Likert Scale, which was later recorded into three categories (agree, neutral and disagree).

Pain knowledge was assessed by the Dutch Language Version of the Pain Knowledge Questionnaire (PKQ-DLV) (De Rond et al. 2000b). The PKQ-DLV has been shown acceptable levels of validity and reliability (De Wit 1995). Although the PKQ-DLV was originally designed for use with cancer patients, the questions seemed suitable to test the basic knowledge of nurses and physicians. The PKQDLV includes eight statements measuring knowledge about cancer pain and pain management, and these were answered on a 5-point Likert scale ('strongly agree', 'agree', 'not agree/not disagree', 'disagree', 'strongly disagree'). Before transforming the answers into a $0-100$ scale, some items were recoded. A total score was computed for overall pain knowledge.

Attitudes towards pain and pain management were assessed using the Pain Attitude Inventory (PAI) (De Rond et al. 2000b). This questionnaire has seven statements which measure nurses' and physicians' opinions on several aspects of pain, including the quality of pain management and nurses' role in pain management. The questions (formulated as statements) were answered on a 5-point Likert scale ('strongly agree', 'agree', 'not agree/not disagree', 'disagree', 'strongly disagree'), which was later recoded into three categories (agree, neutral and disagree). 


\section{Statistical analysis}

Data were analysed using the Statistical Package for the Social Sciences for Windows (SPSS) version 9·0. Descriptive statistics were used to evaluate nurses' and physicians' sociodemographic characteristics. Differences between nurses' pain knowledge at pretest and post-test were analysed with the paired $t$-test, and nurses' attitudes with the chisquare and other nonparametric tests (Wilcoxon sign test).

\section{Results}

\section{Sociodemographic characteristics of nurses and physicians}

Of the 277 nurses in the wards which were invited for the education programme, $244(88.1 \%)$ participated in the programme. Six months later, 236 nurses received the posttest questionnaire, of whom $201(85 \cdot 2 \%)$ returned the questionnaire. To study nurses' pain knowledge and attitude, complete pretest and post-test data were needed for the analysis; due to the turnover rate only 130 nurses were available at both times. The mean age of these nurses was $32.9(\mathrm{SD}=8.3)$ years and the mean professional nursing experience was $8 \cdot 9(\mathrm{SD}=7 \cdot 8)$ years. Those who completed both the pretest and post-test were older $(P<0.001)$, had more professional working experience $(P<0.01)$, and were more often registered nurses $(P<0.001)$ than those who completed only a pretest or post-test questionnaire.

Of the 115 physicians, $68(59 \cdot 1 \%)$ returned the questionnaire. Their mean age was $36.9(\mathrm{SD}=10.6)$ years and the mean professional experience was $7(\mathrm{SD}=8 \cdot 4)$ years. Most of the physicians who returned the questionnaire were general physicians who had not yet completed their specialization (Table 1).

\section{Implementation of daily pain assessment}

In the first 5 months, nurses assessed pain on a daily basis in $75-82 \%$ of the patients. In the sixth month, this percentage gradually decreased and reached $59 \%$ in the seventh month (Figure 1). Nurses' compliance with daily pain assessment depended on care setting and hospital: nurses from surgical wards were less compliant after the first months than those from medical wards. Differences were also found between the five hospitals: compliance ranged from $36 \%$ to $99 \%$, and in three hospitals nurses noted the pain scores in less than $75 \%$ of patients during a 3 -month period.

The DPAQ was completed by 201 nurses and 68 physicians (Table 2). Results show that both nurses and physicians had a
Table 1 Sociodemographic characteristics of nurses and physicians

\begin{tabular}{|c|c|c|}
\hline & $\begin{array}{l}\text { Nurses } \\
(n=130)\end{array}$ & $\begin{array}{l}\text { Physicians } \\
(n=68)\end{array}$ \\
\hline \multicolumn{3}{|l|}{ Gender $(n, \%)$} \\
\hline Male & $15(11.5 \%)$ & $44(64 \cdot 7 \%)$ \\
\hline Female & $115(88 \cdot 5 \%)$ & $23(33 \cdot 8 \%)$ \\
\hline Missing or unknown & - & $1(1 \cdot 5 \%)$ \\
\hline Age in years (mean, SD) & $32 \cdot 9(8 \cdot 3)$ & $36 \cdot 9(10 \cdot 6)$ \\
\hline $\begin{array}{l}\text { Professional experience } \\
\text { in years (mean, SD) }\end{array}$ & $8 \cdot 9(7 \cdot 8)$ & $7 \cdot 0(8 \cdot 4)$ \\
\hline \multicolumn{3}{|l|}{ Educational level $(n, \%)$} \\
\hline Student nurse & $6(4 \cdot 6 \%)$ & \\
\hline In-service education & $96(73.9 \%)$ & \\
\hline Other education & $28(21 \cdot 5 \%)$ & \\
\hline \multicolumn{3}{|l|}{ Care setting $(n, \%)$} \\
\hline Medical ward & $65(50 \cdot 0 \%)$ & $39(57 \cdot 4 \%)$ \\
\hline Surgical ward & $58(44 \cdot 6 \%)$ & $29(42 \cdot 6 \%)$ \\
\hline Combined ward & $7(5 \cdot 4 \%)$ & \\
\hline
\end{tabular}

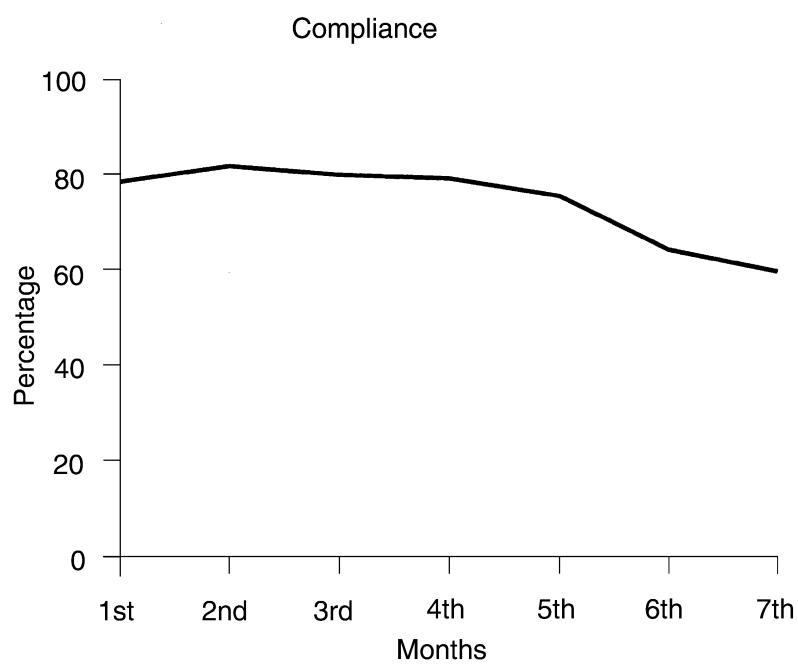

Figure 1 Nurses' professional compliance with daily pain assessment over 7 months.

positive attitude towards daily pain assessment: $84.6 \%$ of nurses and $79.4 \%$ of physicians stated that daily pain assessment is important, $67.7 \%$ of nurses stated that they always perform pain assessment, and $77.6 \%$ of nurses and $64.7 \%$ of physicians wanted to continue with daily pain assessment in future.

According to $83.6 \%$ of the nurses, daily pain assessment fits in easily with their daily routine, and $78.1 \%$ thought it useful to record pain scores on a diagram on the vital signs chart. A majority of nurses had no problem with eliciting a pain score, and around $50 \%$ of both nurses and physicians 
Table 2 Results of the Daily Pain Assessment Questionnaire

\begin{tabular}{|c|c|c|}
\hline & $\begin{array}{l}\text { Nurses, } n(\%) \\
(n=201)\end{array}$ & $\begin{array}{l}\text { Physicians, } n(\%) \\
(n=68)\end{array}$ \\
\hline \multicolumn{3}{|l|}{ Attitude towards daily pain assessment } \\
\hline I think that pain assessment is important* & $170(84 \cdot 6)$ & $54(79 \cdot 4)$ \\
\hline I always perform the pain assessment & $136(67 \cdot 7)$ & NA \\
\hline In future too, nurses should ask for a pain score each day & $156(77 \cdot 6)$ & $44(64 \cdot 7)$ \\
\hline \multicolumn{3}{|l|}{ Feasibility of daily pain assessment } \\
\hline Daily pain assessment fits in with the nurses' daily routine & $168(83.6)$ & NA \\
\hline Daily pain assessment takes additional time & $33(16 \cdot 4)$ & NA \\
\hline Recording of the pain scores in diagram on the vital signs chart is useful & $157(78 \cdot 1)$ & $50(73 \cdot 5)$ \\
\hline Patients find it easy to give a pain score & $33(16 \cdot 4)$ & $17(25)$ \\
\hline The pain score given by the patient often differs from what I consider it to be & $56(27 \cdot 9)$ & $14(20 \cdot 6)$ \\
\hline Physicians make adequate use of the pain assessment & $31(15 \cdot 4)$ & $18(26 \cdot 5)$ \\
\hline During rounds, I always look at the recorded pain scores & NA & $32(47 \cdot 1)$ \\
\hline \multicolumn{3}{|l|}{ Eliciting a pain score } \\
\hline It is difficult to ask for a pain score when you expect patients to be in pain & $29(14 \cdot 4)$ & NA \\
\hline It is bothersome to ask for a pain score when patients do not have pain & $47(23 \cdot 4)$ & NA \\
\hline \multicolumn{3}{|l|}{ Timing of daily pain assessment } \\
\hline \multicolumn{3}{|l|}{ Asking for 'pain at the present moment' is preferable to asking for average } \\
\hline pain during the past 24 hours & $87(43 \cdot 3)$ & $30(44 \cdot 1)$ \\
\hline I consider asking for pain intensity twice a day appropriate & $107(53 \cdot 2)$ & $36(52 \cdot 9)$ \\
\hline \multicolumn{3}{|l|}{ Effects of daily pain assessment on communication } \\
\hline \multicolumn{2}{|l|}{ Since the introduction of daily pain assessment, pain is more often discussed } & NA \\
\hline \multicolumn{3}{|l|}{ Since the introduction of daily pain assessment, pain is more often reported in } \\
\hline \multicolumn{3}{|l|}{ Since the introduction of daily pain assessment, pain is more often discussed } \\
\hline \multicolumn{3}{|l|}{ Since the introduction of daily pain assessment, pain is more often discussed during } \\
\hline \multicolumn{3}{|l|}{ Since the introduction of daily pain assessment, pain is more often reported in the } \\
\hline \multicolumn{3}{|l|}{ Since the introduction of daily pain assessment, nurses raise the issue of pain more } \\
\hline \multicolumn{3}{|l|}{ Since the introduction of daily pain assessment, patients raise the issue of pain more } \\
\hline
\end{tabular}

"Percentages of nurses and physicians who agreed with the statement. NA: not applicable.

found the timing of daily pain assessment appropriate. Only $16.4 \%$ of nurses reported that it seemed easy for patients to give a pain score. It was striking that only $15.4 \%$ of nurses were satisfied with the way physicians used the pain assessment, while $47 \cdot 1 \%$ of physicians claimed that they checked recorded pain scores daily.

Concerning communication, about $46 \%$ of nurses and $37 \%$ of physicians communicated more frequently with colleagues as a result of the daily pain assessment. Although only $15.4 \%$ of nurses reported that physicians make adequate use of the daily pain assessment, $39 \cdot 8 \%$ thought that pain is more often discussed during rounds with the physician.
According to $50 \%$ of physicians, communication with nurses about pain improved. Communication with patients about pain improved according to $40.3 \%$ of nurses and $16.2 \%$ of physicians.

Nurses from medical wards had a more positive attitude towards daily pain assessment $(P<0.001)$ and were more positive about the effects of daily pain assessment on communication $(P<0.001)$ compared with their colleagues from surgical wards. There were also differences between the five hospitals. In one hospital, nurses were more positive about all aspects of daily pain assessment compared with the others. In another hospital, nurses were more negative about 
Table 3 Results of Pain Knowledge Questionnaire-Dutch Language Version of nurses $(n=130)$ and physicians $(n=68)$

\begin{tabular}{|c|c|c|c|c|}
\hline & \multicolumn{3}{|l|}{ Nurses } & \multirow{2}{*}{$\begin{array}{l}\text { Physicians, } \\
\text { mean (SD) }\end{array}$} \\
\hline & Pretest, mean (SD) & Post-test, mean $(\mathrm{SD})$ & $P$-value & \\
\hline Cancer pain can be effectively relieved & $77 \cdot 8(14 \cdot 3)^{*}$ & $79 \cdot 8(15 \cdot 8)$ & $\mathrm{NS}^{\dagger}$ & $76 \cdot 2(17 \cdot 5)$ \\
\hline Pain medication should be given only when pain is severe & $83 \cdot 2(19 \cdot 6)$ & $89 \cdot 3(15 \cdot 9)$ & $<0 \cdot 01$ & $82 \cdot 0(22 \cdot 9)$ \\
\hline $\begin{array}{l}\text { Most cancer patients who take pain medication, will becom } \\
\text { addicted over time }\end{array}$ & $62 \cdot 6(26 \cdot 9)$ & $78 \cdot 9(23 \cdot 4)$ & $<0 \cdot 001$ & $76 \cdot 5(23 \cdot 8)$ \\
\hline $\begin{array}{l}\text { It is important to give the lowest amount of medicine possil } \\
\text { save larger doses for later when the pain is worse }\end{array}$ & $54 \cdot 2(30 \cdot 1)$ & $65 \cdot 6(31 \cdot 7)$ & $<0 \cdot 001$ & $51 \cdot 2(34 \cdot 3)$ \\
\hline $\begin{array}{l}\text { It is better to give pain medications around the clock } \\
\text { (on a schedule) rather than only when needed }\end{array}$ & $85 \cdot 6(21 \cdot 1)$ & $85 \cdot 8(23 \cdot 0)$ & NS & $78.9(28.9)$ \\
\hline $\begin{array}{l}\text { Treatments other than medications (such as massage, heat, } \\
\text { relaxation) can be effective for relieving pain }\end{array}$ & $82 \cdot 5(18 \cdot 5)$ & $82 \cdot 1(20 \cdot 5)$ & NS & $81 \cdot 5(18 \cdot 4)$ \\
\hline Patients are often prescribed too much pain medicine ${ }^{*}$ & $62 \cdot 8(25 \cdot 0)$ & $71 \cdot 3(21 \cdot 8)$ & $<0 \cdot 001$ & $58.6(28.9)$ \\
\hline $\begin{array}{l}\text { Prescriptions for the use of pain medicine can be adjusted b } \\
\text { the patient, without consulting the general practitioner/ } \\
\text { specialist/(district) nurse }\end{array}$ & $59 \cdot 7(30 \cdot 5)$ & $66 \cdot 7(28 \cdot 0)$ & $<0.05$ & $53 \cdot 6(32 \cdot 0)$ \\
\hline Total score & $71 \cdot 1(12 \cdot 3)$ & $77 \cdot 3(11 \cdot 4)$ & $<0.001$ & $69 \cdot 7(12 \cdot 4)$ \\
\hline
\end{tabular}

*Higher scores indicate better pain knowledge; † Not significant; $\ddagger$ Statements were recorded.

the feasibility of daily pain assessment $(P<0.05)$, timing of daily pain assessment $(P<0.05)$, and effects of daily pain assessment $(P<0.001)$.

\section{Pain knowledge}

Overall scores on the PKQ-DLV at pretest ranged from $37 \cdot 5$ to $100($ mean $=71 \cdot 1 ; \mathrm{SD}=12 \cdot 3)$ (Table 3$)$. The lowest score was for the item 'giving the lowest amount of medicine possible' $(54 \cdot 2)$ and the highest score was for 'pain medication should be given around the clock' (85.6).

Results showed that nurses' pain knowledge increased after they had followed the pain education programme: mean increase from $71 \cdot 1$ to $77 \cdot 3(P<0 \cdot 001)$. Item analysis showed improved knowledge on the items: 'psychological addiction is inevitable over time' $(P<0.001)$; 'giving the lowest amount of medicine possible' $(P<0.001)$; 'patients are often overmedicated' $(P<0.001)$; 'medication only for severe pain' $(P<0.05)$; and 'prescriptions can be changed by patients themselves' $(P<0.05)$.

Because they did not follow the education programme, we have only one assessment of physicians (Table 3). Physicians' mean total score was $69 \cdot 7(\mathrm{SD}=12 \cdot 4)$. They scored low on the items 'giving the lowest amount of medicine possible' (51.2) and 'prescriptions can be adjusted without consulting caregivers' (53.6), and high on 'medication only for severe pain' $(82 \cdot 0)$ and 'treatments other than medications can be effective' $(81 \cdot 5)$.

\section{Attitudes towards pain management}

Table 4 gives the results of the PAI. At pretest, $53 \cdot 1 \%$ of nurses felt that most patients receive less pain medication than necessary. However, $64.6 \%$ evaluated the quality of pain management on their ward as good. Only $60 \%$ felt that nurses had sufficient knowledge and skills to relieve pain, thus confirming the need for pain education. All nurses thought that they played an important role in pain relief, and were more positive about the attention they gave to patients' pain complaints $(78.5 \%)$ than that of physicians $(52 \cdot 3 \%)$.

After implementation of the programme, nurses' pain attitudes changed. At pretest, 33.1\% felt that most patients receive adequate pain treatment. After implementation of daily pain assessment and after being educated about pain, this percentage increased to $48.5 \%(P<0.01)$. According to $64.6 \%$ of nurses at pretest and $76.9 \%$ at post-test, the quality of pain management on their ward is good $(P<0.05)$. At pretest, $78.5 \%$ felt that they paid enough attention to patients' pain complaints; at post-test, $90.8 \%$ felt that they paid enough attention $(P<0 \cdot 01)$. The proportion of nurses who believed that they had sufficient knowledge and skills to relieve pain increased from $60 \%$ at pretest to $70.8 \%$ at posttest $(P<0.05)$.

Physicians were positive about nurses' role in pain management $(97 \cdot 1 \%)$, and the attention nurses $(89.7 \%)$ and physicians $(70.6 \%)$ give to patients' pain complaints. The 
Table 4 Results of Pain Attitude Inventory (PAI) of nurses $(n=130)$ and physicians $(n=68)$

\begin{tabular}{|c|c|c|c|c|}
\hline & \multicolumn{3}{|l|}{ Nurses } & \multirow{2}{*}{$\begin{array}{l}\text { Physicians, } \\
n(\%)\end{array}$} \\
\hline & Pretest, $n(\%)$ & Post-test, $n(\%)$ & $P$-value & \\
\hline Which statement is applicable & & & $<0 \cdot 01$ & \\
\hline Most patients receive more pain medication than necessary & $15(11 \cdot 5)$ & $8(6 \cdot 2)$ & & $3(4 \cdot 4)$ \\
\hline Most patients receive less pain medication than necessary & $69(53 \cdot 1)$ & $53(40 \cdot 8)$ & & $30(44 \cdot 1)$ \\
\hline Most patients receive adequate pain treatment & $43(33 \cdot 1)$ & $63(48 \cdot 5)$ & & $34(50)$ \\
\hline Missing or unknown & $3(2 \cdot 3)$ & $6(4 \cdot 6)$ & & $1(1 \cdot 5)$ \\
\hline What is your opinion about the quality of pain management on your ward? & & & $<0 \cdot 05$ & \\
\hline Good & $84(64 \cdot 6)$ & $100(76 \cdot 9)$ & & $55(80 \cdot 8)$ \\
\hline Not good/not poor & $42(32 \cdot 3)$ & $24(18 \cdot 5)$ & & $11(16 \cdot 2)$ \\
\hline Poor & $3(2 \cdot 3)$ & $5(3 \cdot 8)$ & & $1(1 \cdot 5)$ \\
\hline Missing or unknown & $1(0 \cdot 8)$ & $1(0 \cdot 8)$ & & $1(1 \cdot 5)$ \\
\hline Nurses pay enough attention to patients' pain complaints* & $102(78 \cdot 5)$ & $118(90 \cdot 8)$ & $<0 \cdot 01$ & $61(89 \cdot 7)$ \\
\hline Nurses have sufficient knowledge and skills to relieve pain & $78(60)$ & $92(70 \cdot 8)$ & $<0 \cdot 05$ & $17(25)$ \\
\hline Nurses play an important role in pain relief & $130(100)$ & $129(99 \cdot 2)$ & $\mathrm{NS}^{\dagger}$ & $66(97 \cdot 1)$ \\
\hline Physicians pay enough attention to patients' pain complaints & $68(52 \cdot 3)$ & $70(53 \cdot 8)$ & NS & $48(70 \cdot 6)$ \\
\hline Physicians have sufficient knowledge and skills to relieve pain & - & $94(72 \cdot 3)$ & - & $47(69 \cdot 1)$ \\
\hline
\end{tabular}

*Percentages of nurses who agreed with the statement; $†$ Not significant.

majority of physicians were of the opinion that the knowledge and skills of physicians regarding pain relief is sufficient $(69 \cdot 1 \%)$, but only $25 \%$ considered that nurses have sufficient knowledge and skills to relieve pain.

\section{Discussion}

The rationale for this programme was lack of pain knowledge in both nurses and physicians, and the absence of a method to assess pain systematically. It has been shown previously that educating nurses about pain improves pain knowledge and that it is possible to implement daily pain assessment in a research setting (De Rond et al. 1999, 2000b). Implementation of daily pain assessment in a clinical setting, without the aid of research nurses, has not been properly studied in a heterogeneous population. Moreover, the current study investigated the long-term effects of implementing daily pain assessment combined with a nursing pain education programme.

Our study showed that implementation of daily pain assessment in clinical practice is possible. Nurses' professional compliance with daily pain assessment was satisfactory, but gradually decreased to $59 \%$ after 7 months. Apparently, daily pain assessment had lost its novelty and incentives are needed to motivate nurses to continue with daily pain assessment. Only by means of a long-term follow-up can the standard of assessing pain in at least $75 \%$ of the patients daily be achieved. Therefore, a
Continuous Quality Assessment/Improvement process should be used (Miaskowski \& Donovan 1992, Bookbinder et al. 1996).

Both nurses and physicians evaluated the implementation of daily pain assessment as positive. Nurses were more positive about several aspects than physicians, particularly about the beneficial effect of daily pain assessment on communication with patients. Nurses asked for the pain score, so patients probably discussed pain more readily with them than with physicians.

The results show that the level of nurses' and physicians' pain knowledge is moderate. Surprisingly, prejudices about medication appear to persist among both groups, despite efforts to counteract these. They think that patients should be given the lowest amount of medicine possible, and that patients are often overmedicated. Nurses and physicians have a positive attitude towards pain management. However, on the one hand nurses are positive about the quality of pain management on their ward, but also believe that most patients receive less pain medication than they need. This may be explained by the fact that the majority of patients are satisfied with their pain management despite high pain levels (Miaskowski et al. 1994, Ward \& Gordon 1994).

Nurses' pain knowledge and attitudes improved as a result of the pain education programme and implementation of daily pain assessment. Studies by Titler et al. (1994), Bach (1995), Dufault et al. (1995), and Bookbinder et al. (1996) also found an increase in pain knowledge after nurses had 
followed an education programme. The $6 \cdot 2$ increase in score on the knowledge questionnaire may seem moderate, but on important pain management issues there was a substantial increase. With regard to attitudes, nurses were more satisfied about the quality of pain management, about their own knowledge and skills to relieve pain, and about the attention they paid to patients' pain complaints after implementation of the PMP.

\section{Study limitations}

Although the results of the current study are promising, some limitations and shortcomings should be addressed. First, there was no control group in this study. Without a control group it is impossible to state that the increase in pain knowledge was not caused by other factors than the education programme. On the other hand, nurses from 11 wards in five hospitals were included in this study, so one can assume that other factors are neutralized. Second, the results from the nurses cannot easily be compared with those from physicians because physicians were only surveyed at post-test and did not follow the education programme. Third, the PKQ-DLV was originally designed to measure patients' cancer pain knowledge, and the PAI has not been extensively used before. Therefore, the suitability of both questionnaires is debatable, but definite beneficial effects on nurses of the programme were found using these two questionnaires. Fourth, the sociodemographic characteristics of the nurses who filled in both pretest and post-test differed from those who completed only a pretest or post-test questionnaire. The turnover rate of nurses is high: we have 7-month follow-up data on about half the nurses in our study population. However, these nurses can be considered the backbone of the wards.

\section{Conclusion}

Based on this study, it is concluded that it is possible to implement the PMP in a normal clinical setting. The study demonstrated that both nurses and physicians are positive about daily pain assessment and want to continue with it. Furthermore, the study showed that the level of nurses' and physicians' knowledge about pain and pain management is moderate. Educating nurses about pain and pain management proved to be effective in increasing nurses' knowledge and satisfaction about the quality of pain treatment. Based on these results, participating hospitals are advised to continue and extend the PMP and other hospitals are encouraged to implement it. To this end, an extensive manual has been developed incorporating a teaching video for nurses in which patients, nurses and physicians explain daily pain assessment ${ }^{1}$.

\section{Acknowledgements}

This study was supported by a grant from the National Centre for Nursing \& Care. The authors thank all nurses and physicians for their co-operation. We extend special thanks to the nursing departments of the Slotervaart Hospital, St Lucas Andreas Hospital (location Andreas and location St Lucas), BovenIJ Hospital, and Rode Kruis Hospital. Special thanks are due to the co-ordinators of the Programme: I. de Vries and M. Inghels, Slotervaart Hospital; H. van Orden and I. Bastiaanse, St Lucas Andreas Hospital (location Andreas); C. de Boer, BovenIJ Hospital; N. Drent, Rode Kruis Hospital; W. de Ruijter, St Lucas Andreas Hospital (location St Lucas).

\section{References}

American Pain Society Quality of Care Committee (1995) Quality improvement guidelines for treatment of acute pain and cancer pain. Journal of the American Medical Association 274, 1874-1880.

Bach D.M. (1995) Implementation of the Agency for Health Care Policy and Research postoperative pain management guideline. Nursing Clinics of North America 30, 515-527.

Bookbinder M., Coyle N., Kiss M., Goldstein M.L., Holritz K., Thaler H., Gianella A., Derby S., Brown M., Racolin A., Ho M.N. \& Portenoy R.K. (1996) Implementing national standards for cancer pain management: program model and evaluation. Journal of Pain and Symptom Management 12, 334-347.

Campese C. (1996) Development and implementation of a pain management program. AORNJ 64, 931-940.

Caswell D.R., Williams J.P., Vallejo M., Zaroda T., McNair N., Keckeisen M., Yale C. \& Cryer H.G. (1996) Improving pain management in critical care. Journal of Quality Improvement 22, 702-712.

Clarke E.B., French B., Bilodeau M.L., Capasso V.C., Edwards A. \& Empoliti J. (1996) Pain management knowledge, attitudes and clinical practice: the impact of nurses' characteristics and education. Journal of Pain and Symptom Management 11, 18-31.

Coyle N., Adelhardt J., Foley K.M. \& Portenoy R.K. (1990) Character of terminal illness in the advanced cancer patient: pain and other symptoms during the last four weeks of life. Journal of Pain and Symptom Management 5, 83-93.

De Rond M., de Wit R., van Dam F., van Campen B., den Hartog Y., Klievink R., Nieweg R., Noort J., Wagenaar M. \& Van Campen B., (1999) Daily pain assessment: value for nurses and patients. Journal of Advanced Nursing 29, 436-444.

${ }^{1}$ The manual can be obtained from the Comprehensive Cancer Centre Amsterdam, Plesmanlaan 125, 1066 CX Amsterdam (Tel.: + 31203462525 ) or the Pain Expertise Centre, University Hospital Rotterdam, Dr Molewaterplein 40, 3015 GD Rotterdam (Tel.: + 311046392 22), The Netherlands. 
De Rond M.E.J., de Wit R., van Dam F.S.A.M. \& Muller M.J. (2000a) A Pain Monitoring Program for nurses: effects on communication, assessment and documentation of patients' pain. Journal of Pain and Symptom Management 20, 424-439.

De Rond M.E.J., de Wit R., van Dam F.S.A.M., van Campen B.Th.M., den Hartog Y.M. \& Klievink R.M.A. (2000b) A Pain Monitoring Program for nurses: effects on nurses' pain knowledge and attitude. Journal of Pain and Symptom Management 19, 457-467.

De Rond M.E.J., de Wit R., van Dam F.S.A.M. \& Muller M.J. (2001) A Pain Monitoring Program for nurses: effect on patients' pain. The Clinical Journal of Pain.

De Wit R. (1995) Development of the Dutch Language Version of Ferrell's Pain Knowledge Questionnaire. Unpublished Report. The Netherlands Cancer Institute/Antoni van Leeuwenhoek Hospital, Amsterdam.

De Wit R., van Dam F., Huijer Abu-Saad H., Vielvoye-Kerkmeer A. \& Mattern C. (1999) The treatment of chronic cancer pain in a cancer hospital in the Netherlands. Journal of Pain and Symptom Management 17, 333-350.

Dietrick-Gallagher M., Polomano R. \& Carrick L. (1994) Pain as a quality management initiative. Journal of Nursing Care Quality 9 , 30-42.

Donovan M.I. (1985) Nursing assessment of cancer pain. Seminars of Oncology Nursing 1, 109-115.

Dorrepaal K.L., Aaronson N.K. \& van Dam F.S.A.M. (1989) Pain experience and pain management among hospitalized cancer patients: a clinical study. Cancer 63, 593-598.

Dufault M.A., Bielecki C., Collins E. \& Willey C. (1995) Changing nurses' pain assessment practice: a collaborative research utilization approach. Journal of Advanced Nursing 21, 634-645.

Ferrell B.R. \& McCaffery M. (1997) Nurses' knowledge about equianalgesia and opioid dosing. Cancer Nursing 20, 201-212.

Ferrell B., Whedon M. \& Rollins B. (1995) Pain and quality assessment/improvement. Journal of Nursing Care Quality 9, 69-85.

Fife B.L., Irick N. \& Painter J.O. (1993) A comparative study of the attitudes of physicians and nurses toward the management of cancer pain. Journal of Pain and Symptom Management 8, 132-139.

Furstenberg C.T., Ahles T.A., Whedon M.B., Pierce K.L., Dolan M., Roberts L. \& Silberfarb P.M. (1998) Knowledge and attitudes of health-care providers toward cancer pain management: a comparison of physicians, nurses, and pharmacists in the State of New
Hampshire. Journal of Pain and Symptom Management 15, 335-349.

Jacox A., Carr D. \& Payne R. (1994) Special report: new clinicalpractice guidelines for the management of pain in patients with cancer. New England Journal of Medicine 330, 651-655.

Jacox A., Ferrell B., Heidrich G., Hester N. \& Miaskowski C. (1992) A guideline for the nation: managing acute pain. American Journal of Nursing 5, 49-55.

Juhl I.U., Christensen B.V., Bülow H.H., Wilbek H., Dreijer N.C. \& Egelund B. (1993) Postoperative pain relief, from the patients' and the nurses' point of view. Acta Anaesthesiologica Scandinavica 37, 404-409.

Kuhn S., Cooke K., Collins M., Jones J.M. \& Mucklow J.C. (1990) Perceptions of pain relief after surgery. British Medical Journal 300, 1687-1690.

Lebovits A.H., Florence I., Bathina R., Hunko V., Fox M.T. \& Bramble C.Y. (1997) Pain knowledge and attitudes of healthcare providers: practice characteristic differences. Clinical Journal of Pain 13, 237-243.

Lin C.C. \& Ward S.E. (1995) Patient-related barriers to cancer pain management in Taiwan. Cancer Nursing 18, 16-22.

McCaffery M. \& Ferrell B.R. (1995) Nurses' knowledge about cancer pain: a survey of five countries. Journal of Pain and Symptom Management 10, 356-369.

McCaffery M. \& Ferrell B.R. (1997) Nurses' knowledge of pain assessment and management: how much progress have we made? Journal of Pain and Symptom Management 14, 175-188.

Miaskowski C. \& Donovan M. (1992) Implementation of the American Pain Society Quality Assurance Standards for Relief of Acute Pain and Cancer Pain in Oncology Nursing Practice. Oncology Nursing Forum 19, 411-415.

Miaskowski C., Nichols R., Brody R. \& Synold T. (1994) Assessment of patient satisfaction utilizing the American Pain Society's Quality Assurance Standards on acute and cancer-related pain. Journal of Pain and Symptom Management 9, 5-11.

Titler M.G., Moss L., Greiner J., Alpen M., Jones G., Olson K., Hauer M., Phillips C. \& Megivern K. (1994) Research utilization in critical care: an exemplar. Clinical Issues 5, 124-132.

Von Roenn J.H., Cleeland C.S., Gonin R., Hatfield A.K. \& Pandya K.J. (1993) Physician attitudes and practice in cancer pain management: a survey from the Eastern Cooperative Oncology Group. American College of Physicians 119, 121-126.

Ward S.E. \& Gordon D. (1994) Application of the American Pain Society quality assurance standards. Pain 56, 299-306. 